\title{
Effects of the Transcendental Meditation Program on Substance Use among University Students
}

\author{
David A. F. Haaga, ${ }^{1}$ Sarina Grosswald, ${ }^{2}$ Carolyn Gaylord-King, ${ }^{2}$ Maxwell Rainforth,, \\ Melissa Tanner, ${ }^{1}$ Fred Travis, ${ }^{3,4}$ Sanford Nidich, ${ }^{2}$ and Robert H. Schneider ${ }^{2}$ \\ ${ }^{1}$ Department of Psychology, American University, Asbury Building, Washington, DC 20016-8062, USA \\ ${ }^{2}$ Center for Natural Medicine and Prevention, Maharishi University of Management Research Institute, Maharishi Vedic City, \\ IA 52556, USA \\ ${ }^{3}$ Center for the Brain, Consciousness, and Cognition, 1000 North 4th Street, Fairfield, IA 52557, USA \\ ${ }^{4}$ Maharishi University of Management Research Institute, Maharishi Vedic City, IA 52556, USA
}

Correspondence should be addressed to David A. F. Haaga, dhaaga@american.edu

Received 18 October 2010; Accepted 20 January 2011

Academic Editor: P. Holvoet

Copyright () 2011 David A. F. Haaga et al. This is an open access article distributed under the Creative Commons Attribution License, which permits unrestricted use, distribution, and reproduction in any medium, provided the original work is properly cited.

\begin{abstract}
A randomized wait-list controlled trial $(N=295$ university students $)$ of the effects of the Transcendental Meditation program was conducted in an urban setting. Substance use was assessed by self-report at baseline and 3 months later. For smoking and illicit drug use, there were no significant differences between conditions. For alcohol use, sex X intervention condition interactions were significant; TM instruction lowered drinking rates among male but not female students. TM instruction could play a valuable role in reducing alcohol use among male university students. Limitations are noted, along with suggestions for further research.
\end{abstract}

\section{Introduction}

Substance use on American college campuses is a significant public health problem with adverse effects including but not limited to impaired academic performance, interpersonal violence, acute injuries, and increased risk of mortality [1]. Cigarette smoking is an established risk factor for coronary heart disease, among other disease states [2]. Clinical researchers have accordingly devoted extensive effort to developing and refining methods of treatment or means of secondary prevention to reduce substance use and its negative consequences [3].

No matter how well such intervention programs work, they can only help those who enroll in them. Anyone choosing to participate in such a program must have identified substance use as a problem on which they would like to work. This conclusion could be prompted by advice from a parent, teacher, or physician, the concern of a roommate, mandate from a campus authority (e.g., in the wake of violation of an alcohol policy), or simply the burgeoning awareness that substance use has become excessive and is interfering in one's life. Unfortunately, this awareness, and the motivation to reduce substance use, may emerge only after an extensive period of problematic substance use.

Therefore, a potentially important contribution could be made by identifying an intervention method that has the effect of reducing substance use among college students but does not require that participants be motivated (at least initially) to make changes in this regard. Theory and past research suggest that the Transcendental Meditation (TM) technique may comprise such an intervention. TM practice involves a mental technique used twice daily for twenty minutes. It is described as a simple, natural, and effortless practice whereby a person experiences a state of restful alertness. TM practice involves two components: a suitable sound "mantra" specifically chosen for its facilitation of the 
process of settling the mind and a precise technique for using it. Thinking the sound leads the meditator to experience quieter and quieter aspects of his or her awareness, eventually experiencing complete silence.

TM instruction does not directly target changes in substance use, but it has been hypothesized that the technique should nonetheless lead to reduced substance use. In particular, "...these effects occur naturally as a by-product of neutralizing stress and experiencing greater inner fulfillment, with no attempt made to manipulate behavior, beliefs, or attitudes. As inner contentment and fulfillment grow, the need to seek gratification outside of one's self naturally subsides and addictive behavior falls off." [4, page 36].

Both qualitative [5] and quantitative [4] reviews of effects of TM practice on substance use have yielded strikingly positive outcomes. For instance, a meta-analysis of 19 studies showed, at an average followup of 10 months, mean effect sizes (relative to control conditions) of .55 for alcohol consumption, .87 for cigarette smoking, and .83 for illicit drug consumption [4]. In each case these effects compared favorably to effect sizes from meta-analyses of a range of other interventions.

Nevertheless, the empirical case for the TM program as a useful intervention in reduction of substance use on college campuses remains uncertain. Of the 19 studies included in a systematic review and meta-analysis [4], for example, 13 either lacked control conditions or used control conditions not involving random assignment (e.g., "yoked" peer controls, in which a meditating participant recruits a nonmeditating friend to serve in the comparison condition). Only six studies included random assignment to conditions, making it possible to ascribe effects with confidence to the TM program itself rather than preexisting characteristics of those who elect to learn the method.

Of the six randomized experiments, two were conducted in college samples $[6,7]$, only one of which was a published study [7]. In the published study, TM participants significantly decreased their rate of cigarette consumption over a 10 -week period relative to a no-treatment control. However, sample size was small ( $n=18$ per condition), and no information was provided on the number of participants achieving complete abstinence from smoking. Additionally, the project was presented to participants as a study of smoking reduction, and smoking rates were self-monitored, so results are inconclusive with respect to a standard TM program in which smoking is not a content focus. Finally, this study did not provide information on alcohol or other drug use.

In short, TM practice appears to have the potential to fill a niche in the effort to reduce substance use on college campuses by decreasing use even among those not initially seeking a substance abuse treatment program, but the evidence base for such an effect is limited. Therefore, in the context of a randomized controlled trial of the TM program for college students, researching the effects on various health and lifestyle parameters, we examined data on cigarette smoking, illicit drug use, and alcohol use. We hypothesized that students assigned to the TM condition would reduce substance use over a three-month period compared to students assigned to a wait-list control condition.

\section{Materials and Methods}

2.1. Participants. Participants were 295 students from universities in the Washington, DC area who responded to advertisements, newspaper stories, flyers posted on campuses, or public presentations concerning a study of the effects of the Transcendental Meditation program on brain functioning, cognitive development, and health. Effects on these other measures, aside from substance use, will be reported separately. The study was conducted at American University in collaboration with Maharishi University of Management Research Institute and was approved by Institutional Review Boards at both institutions.

Participants had to meet the inclusion criteria of (a) being an undergraduate or graduate student and (b) being enrolled in school through August 2006 (study enrollment began in January 2006). Forty-eight prospective participants were excluded for one or more of the following reasons: (a) systolic blood pressure over 140 or below $90 \mathrm{~mm} \mathrm{Hg}$, (b) diastolic blood pressure over 90 or below $60 \mathrm{~mm} \mathrm{Hg}$, (c) a history of hypertension, (d) history of coronary heart disease, (e) history of hypoglycemia, or (f) history of chronic fainting.

Of the 295 participants who provided informed consent and were randomized to a treatment condition and completed pretesting, 178 (60\%) were women, and $117(40 \%)$ were men. The average age was 25.48 years $(\mathrm{SD}=9.03)$. The majority of participants (62\%) were Caucasian. About onesixth $(16 \%)$ were African-American, while $7 \%$ were AsianAmerican, 7\% "other" race, 4\% Hispanic, and 4\% declined to report race/ethnicity.

\subsection{Measures}

2.2.1. Substance Use. Substance use was measured once at pretreatment and once again at posttreatment by way of a questionnaire embedded in several other self report measures (not relevant to this report). Participants were asked simply "Do you smoke cigarettes?", "Do you use non prescribed drugs (e.g., marijuana, amphetamines, cocaine/ crack)," and "Do you drink alcohol?". Anyone answering "yes" to any of these questions was directed to additional questions about quantity and frequency of recent consumption (cigarettes/day in past week, number of times using nonprescribed drugs in the past month, beers/glasses of wine/shots of hard liquor over the past week).

2.2.2. Adherence. Adherence to the TM technique was measured via self-report at posttesting among those who had received TM instruction. Participants were asked how many minutes in each session they usually practiced the TM technique. They were also asked to describe the regularity of their practice of the TM technique over the preceding week (not at all, less than once/day, once a day, or twice a day). Participants reporting having practiced once a day or twice a day were considered adherent. 
2.3. Procedure. Students who expressed interest in participating in the overall study were scheduled for small group informational and testing sessions at baseline. At this session, a member of the research staff gave an overview of what the study would involve. A member of the TM instructional staff gave a brief description of the TM technique and answered students' questions. Students interested in enrolling then were given detailed information about study procedures, risks, and benefits and completed individual written informed consent with a member of the research staff.

After a 5-minute rest period, prospective participants had three blood pressure measurements taken one minute apart. The average of these three readings was used to determine eligibility for the study. Participants also completed the substance use inventory, demographic and medical history forms, and several other self-report instruments and cognitive ability tests not relevant to this report.

Participants who met the study criteria were subsequently randomized within blocks to (a) immediate TM instruction or (b) wait list/delayed start condition. The blocks used in random assignment were men versus women, crossed with presence versus absence of a diagnosis of attention deficit hyperactivity disorder (ADHD) per selfreport. The ADHD stratification was for the purposes of a separate substudy; 25 participants indicated that they had been diagnosed with ADHD.

Participants paid a reduced course fee of $\$ 50$ at the beginning of TM instruction and were paid $\$ 25$ for each assessment session completed. Assessments were conducted at baseline (pretest) and again approximately 3 months later (posttest) (The initial design plan for this project, the grant funding period, and the consent forms signed by participants were all based on including only the pretest and immediate posttest three months later. Subsequently, an additional year of funding was obtained, and we attempted to conduct a third assessment of the same sample of participants. A separate informed consent procedure was used, and the third assessment constituted a follow-up/maintenance evaluation for the original immediate-TM group, a postinstruction evaluation for the original wait-listed group. However, only 83 participants completed the third assessment (i.e., 28\% of the randomized sample, $39 \%$ of the subsample who had completed the second assessment). Accordingly, we elected not to analyze and report data from the third assessment. Some of the original participants had graduated by the time we were recruiting for a third assessment. Others had left the country for study abroad programs, and others simply lost interest and declined further participation in the study.). All assessments were administered by research staff who were masked to the participant's treatment condition assignment. After the posttest evaluation, wait-list participants were offered TM instruction.

2.3.1. Intervention: The Transcendental Meditation Technique. The Transcendental Meditation (TM) technique is described as a simple, natural, and effortless technique practiced for about 20 minutes, twice a day, while sitting comfortably with the eyes closed [8]. TM practice is intended to take the mind from active levels of thinking to the state of least mental activity. This experience of restful alertness-full self-awareness devoid of customary mental content-is called "Transcendental Consciousness" [9-11]. TM practice is not intended simply as a relaxation method-it also promotes increased alertness. The primary areas of brain activation during TM practice have been localized to prefrontal executive circuits and anterior cingulate attention circuits in an MEG study [12] and EEG coherence studies [13, 14] and in frontal and parietal areas as demonstrated in a preliminary PET study [15]. Other physiological correlates have been reviewed [16].

The TM technique is taught in a series of 7 standardized steps [8]. The preparatory steps include an introductory lecture, which offers a review of previous scientific research on the TM program and a vision of possible benefits through regular practice, a preparatory lecture, which offers a review of the mechanics and origin of the TM technique, and a personal interview, in which a qualified teacher of the TM program gathers basic information from the student to aid with the personalization of instruction. The introductory and preparatory lectures last about 90 minutes and take place in a group setting. The one-on-one personal interview lasts 10 minutes.

The next step in learning the TM technique is personal instruction. In this study, personal instruction was conducted by a male teacher for male students and by a female teacher for female participants. It was believed that having a same-sex instructor would be more comfortable for the one-on-one personal instruction meeting, which lasts about 90 minutes. It is followed by three 90-minute group "checking" sessions. On the first day of checking, verification of the correctness of TM practice and further instruction take place. The goal of the second day of checking is the understanding of the mechanics of the Transcendental Meditation technique from personal experiences. Finally, the goal of the third day of checking is the understanding of the mechanics of development of higher states of wellness and health through the TM program. Once the third checking session was completed, the student was invited to attend individual meetings with the TM instructor to check on the mechanics of the TM practice. These meetings, of about 30 minutes each, are held weekly for the first month after the basic course, then monthly thereafter. Finally, weekly (group) knowledge meetings were available for those who were interested.

2.3.2. Instructors. Two very experienced instructors (one female, one male) taught the TM technique to participants. Each had been practicing the TM technique for over 35 years at the time the study was conducted. Each was initially certified as a TM teacher in the early 1970s by Maharishi Mahesh Yogi after a 6-month in-residence, fulltime training period with him. Both instructors have completed numerous advanced training courses for TM teachers and were recertified as TM teachers in 2005.

2.3.3. Data Analysis. Treatment effects were tested for each substance separately (cigarette smoking, illicit drug use, 
alcohol use). In each case, the subsamples analyzed were those who (a) were using that substance at pretest and (b) completed both pre- and posttest assessments. Chi-squared tests were used to compare the TM and wait-list groups on the frequency with which pretest substance users reported abstinence at posttest. Analyses of covariance were used to test intervention effects on amount of substance use. When sample size permitted, sex differences were evaluated, in view of previous research indicating sex differences in the extent of drug use among college students [17], in the correlates of alcohol use among college students [18], and in response to substance use interventions [19].

\section{Results}

3.1. Preliminary Analyses. Participants were excluded, based on a priori decision rules, if they reported at baseline any of the following: (a) more than 80 cigarettes/day, (b) illicit drug use on more than 90 occasions in the past month, or (c) more than 42 drinks/week, as these reports were considered not believable. Three participants were excluded on this basis. One had claimed illicit drug use 100 times in the past month, another 49 drinks/week and 260 occasions/month of illicit drug use, and the third 92 drinks/week and 210 occasions/month of illicit drug use. All subsequent analyses are based on the remaining 292 participants after this exclusion.

3.2. Pretreatment Equivalence of Groups. To evaluate the success of random assignment, the 147 participants assigned to immediate TM instruction and the 145 participants assigned to wait list were compared on demographic and substance use variables (chi-square tests for discrete measures and $t$ tests for continuous measures). None of these tests approached significance, suggesting that randomization was successful in generating substantially equivalent participant groups at the outset of the study.

Attrition. Of the 292 participants, 218 (75\%) completed the second assessment, after the TM group had received instruction. Table 1 shows the demographic and pretreatment substance use characteristics of completers and attriters. As can be seen in the table, attriters were more likely to have reported at baseline use of illicit drugs in the previous month. Gender, age, and prevalence of smoking and drinking did not differ, nor did rates of use of any substance among those who used at all.

\subsection{Treatment Effects on Smoking}

3.3.1. Abstinence. The sample for this analysis was completers only (i.e., participants with posttest data available), who had reported smoking at the baseline assessment. Only $37(13 \%)$ of our participants smoked cigarettes at baseline, and of these $25(68 \%)$ completed the posttest assessment. Of the 11 smokers in the immediate-TM condition, 3 (27\%) reported abstinence at posttest. Similarly, of the 14 baseline smokers in the wait-list condition, 4 (29\%) reported
TABLE 1: Baseline comparison of completers $(n=218)$ and attriters $(n=74)$.

\begin{tabular}{|c|c|c|c|c|}
\hline & Completers & Attriters & $\begin{array}{c}t \\
\text { (chi-square } \\
\text { test) }\end{array}$ & $P$ \\
\hline$\%$ female & 59 & 63 & $(0.38)$ & .54 \\
\hline Mean Age (SD) & $25.80(9.49)$ & $24.75(7.62)$ & 0.95 & .34 \\
\hline$\%$ smokers & 11 & 16 & $(1.13)$ & .29 \\
\hline $\begin{array}{l}\text { Mean } \\
\text { cigarettes/day } \\
(\mathrm{SD})\end{array}$ & $9.84(12.04)$ & $5.08(3.18)$ & 1.34 & .19 \\
\hline $\begin{array}{l}\% \text { use illicit } \\
\text { drugs }\end{array}$ & 17 & 31 & $(6.74)$ & .01 \\
\hline $\begin{array}{l}\text { Mean drug use } \\
\text { freq/month } \\
\text { (SD) }\end{array}$ & $8.00(11.89)$ & $4.96(5.55)$ & 1.15 & .26 \\
\hline$\%$ drink alcohol & 74 & 71 & $(0.10)$ & .76 \\
\hline $\begin{array}{l}\text { Mean } \\
\text { drinks/week } \\
\text { (SD) }\end{array}$ & $5.57(6.25)$ & $6.25(5.93)$ & 0.71 & .48 \\
\hline
\end{tabular}

Note. Average use figures were calculated only for participants who reported any use of the given substance.

abstinence at posttest, a nonsignificant difference between groups, chi square $(d f=1, N=25)=0.01$, NS.

3.3.2. Smoking Rate. Self-reported smoking rate at posttest was not normally distributed (Kolmogorov-Smirnov $Z=$ $1.56, P<.05$, with skewness $=2.53$ and kurtosis $=5.81)$. For the purposes of inferential statistical analysis, we therefore used transformed data. Taking the natural log of (\# posttest cigarettes/day +1 ) reduced skewness to 0.66 and kurtosis to -0.42 . Treatment condition effects were evaluated in an ANCOVA with condition (TM instruction versus waitlist) as the independent variable, log-transformed pretest cigarettes/day as the covariate, and log-transformed posttest cigarettes per day as the dependent variable. The treatment condition effect was nonsignificant, $F(1,22)=0.05$, NS. Table 2 shows the (untransformed) average cigarettes per day at pretest and posttest among baseline smokers in each condition.

\subsection{Treatment Effects on Illicit Drug Use}

3.4.1. Abstinence. Of the 60 participants who reported illicit drug use at baseline, $37(62 \%)$ provided posttest data, 15 in the TM condition and 22 in the wait-list condition. Of the 15 in the TM condition, 33\% $(n=5)$ reported abstinence from illicit drug use at posttest, compared to $27 \%$ (6 of 22) posttest abstinence in the wait-list condition, a nonsignificant difference, chi square $(d f=1, N=37)=$ 0.16 , NS.

3.4.2. Frequency of Use. Posttest self-reported frequency (over the preceding month) of illicit drug use, among those using at all at baseline, was not normally distributed 
TABLE 2: Smoking and illicit drug use at pretest and posttest among baseline users who completed both assessments.

\begin{tabular}{|c|c|c|c|c|c|}
\hline & & pre-TM & post-TM & pre-WL & post-WL \\
\hline \multirow[t]{3}{*}{$\begin{array}{l}\text { Cigarettes/ } \\
\text { day }\end{array}$} & $\begin{array}{c}\text { Mean } \\
(95 \% \\
\text { CI })\end{array}$ & $\begin{array}{c}8.64 \\
(4.26 \\
13.02)\end{array}$ & $\begin{array}{c}8.64(0) \\
20.38)\end{array}$ & $\begin{array}{l}10.79 \\
(1.98 \\
19.60)\end{array}$ & $\begin{array}{c}9.64(0 \\
19.36)\end{array}$ \\
\hline & SD & 6.52 & 17.47 & 15.25 & 16.83 \\
\hline & $N$ & 11 & 11 & 14 & 14 \\
\hline
\end{tabular}

Illicit drug

use

\begin{tabular}{lccccc} 
Occasions/ & Mean & 5.14 & 2.43 & $9.82(3.25$, & 7.95 \\
month & 95\% & $(3.27$, & $(0.39$, & $16.39)$ & $(2.89$, \\
& $\mathrm{CI})$ & $7.00)$ & $4.47)$ & & $13.01)$ \\
& $\mathrm{SD}$ & 3.37 & 3.69 & 14.82 & 11.42 \\
& $N$ & 15 & 15 & 22 & 22 \\
\hline
\end{tabular}

Note. TM: Transcendental Meditation condition; WL: wait-list condition.

(Kolmogorov-Smirnov $Z=1.67, P<.05$, skewness $=2.43$, kurtosis $=5.62$ ). Taking the natural log of (posttest frequency of use in past month +1 ) reduced skewness to 0.54 and kurtosis to -0.80 . Treatment condition effects were evaluated in an ANCOVA with condition (TM instruction versus waitlist) as the independent variable, log-transformed pretest drug use occasions in the past month as the covariate, and log-transformed posttest drug use frequency as the dependent variable. The treatment condition effect was nonsignificant, $F(1,33)=2.73$, NS. Table 2 shows the (untransformed) average frequency of use of illicit drugs in the past month at pretest and posttest among baseline drug users in each condition.

3.5. Treatment Effects on Drinking. Almost three-fourths (74\%) of our participants reported drinking alcohol at pretest, consistent with other studies of American college samples [20]. Of the 217 participants who reported drinking alcohol at baseline, $161(74 \%)$ completed posttesting. Thus, alcohol was the one substance for which we had enough pretest substance users to conduct meaningful analysis of sex differences in treatment response.

3.5.1. Abstinence. There was a significant three-way interaction of treatment condition $\mathrm{X}$ sex $\mathrm{X}$ posttreatment abstinence, chi square $(d f=1, N=161)=4.71$, $P<.05$. Observed cell frequencies appear in Table 3. Among men, $17 \%$ of those who drank at baseline and were assigned to the TM condition reported abstinence at posttest, a nonsignificantly greater proportion than in the wait-list condition $(6 \%)$, chi square $(d f=1, N=65)=$ 2.28 , NS. Among women, on the other hand, there was a nonsignificant effect in the other direction. Of those who reported drinking at pretest, $4 \%$ reported abstinence at posttest in the TM condition, compared to $14 \%$ in the waitlist condition, chi square $(d f=1, N=96)=2.42$, NS. Combining men and women, in each treatment condition $10 \%$ reported abstinence from alcohol at posttest, chi square $(d f=1, N=161)=0.04$, NS.
TABLe 3: Posttest abstinence from alcohol among male and female baseline drinkers.

\begin{tabular}{lccc}
\hline Condition & Outcome & Men & Women \\
\hline TM & Drinking & 24 & 43 \\
& Abstinent & 5 & 2 \\
\% abstinent (95\% CI) & & $17(4,31)$ & $4(0,10)$ \\
Wait List & Drinking & 34 & 44 \\
& Abstinent & 2 & 7 \\
\% abstinent (95\% CI) & & $6(0,13)$ & $14(4,23)$ \\
\hline
\end{tabular}

Note. Treatment condition $\mathrm{X}$ sex $\mathrm{X}$ posttreatment abstinence interaction significant, chi-square test $(d f=1, N=161)=4.71, P<.05$.

TABLE 4: Drinks per week at pretest and posttest for male and female participants who reported any alcohol use at pretest.

\begin{tabular}{|c|c|c|c|c|c|}
\hline & & pre-TM & post-TM & pre-WL & post-WL \\
\hline \multirow[t]{3}{*}{ Men } & $\begin{array}{c}\text { Mean } \\
(95 \% \\
\text { CI })\end{array}$ & $\begin{array}{c}7.07(4,45 \\
9.69)\end{array}$ & $\begin{array}{c}5.83(2.54 \\
9.12)\end{array}$ & $\begin{array}{c}8.67(5.63 \\
11.71)\end{array}$ & $\begin{array}{l}10.11 \\
(7.05 \\
13.17)\end{array}$ \\
\hline & SD & 6.89 & 8.66 & 8.99 & 9.04 \\
\hline & $\mathrm{N}$ & 29 & 29 & 36 & 36 \\
\hline Women & $\begin{array}{c}\text { Mean } \\
(95 \% \\
\text { CI })\end{array}$ & $\begin{array}{c}4.48(3.36 \\
5.60)\end{array}$ & $\begin{array}{c}4.14(2.71 \\
5.57)\end{array}$ & $\begin{array}{c}3.46(2.36 \\
4.56)\end{array}$ & $\begin{array}{c}3.06(2.05 \\
4.07)\end{array}$ \\
\hline & $\mathrm{SD}$ & 3.72 & 4.76 & 3.87 & 3.55 \\
\hline & $\mathrm{N}$ & 45 & 45 & 50 & 50 \\
\hline
\end{tabular}

Note. TM: Transcendental Meditation condition; WL: wait-list condition.

3.5.2. Drinks per Week. Descriptive statistics for (untransformed) drinks per week at pretest and posttest, separately by gender and by treatment condition, appear in Table 4 .

The distribution of self-reported drinks per week $(M=$ $5.44, \mathrm{SD}=6.97$ ) at posttest was significantly nonnormal, Kolmogorov-Smirnov $Z=2.75, P<.05$, with skewness $=2.15$ and kurtosis $=5.38$. Accordingly, for inferential statistical analyses we utilized transformed data. Taking the natural log of (\# posttest drinks/week +1 ) reduced skewness to .13 and kurtosis to -1.03 .

Analysis of covariance, with transformed drinks/week at posttest as the dependent measure and transformed drinks/week at pretest as the covariate, yielded significant main effects for treatment condition, with TM participants drinking less than did wait-list participants, $F(1,154)=3.93$, $P<.05$, and for sex, with women drinking less than did men, $F(1,154)=4.16, P<.05$. There was also a significant sex X treatment condition interaction, $F(1,154)=5.20$, $P<.05$. We therefore examined treatment condition effects in analyses of covariance conducted separately by sex. For women there was no significant difference between treatment conditions, $F(1,91)=0.13$, NS. For men, however, there was a significant effect of treatment condition, $F(1,62)$ $=7.10, P<.05$. As can be seen in Table 4, the direction of this effect was in favor of the TM condition; drinks per week decreased from pretest to posttest among men in the TM condition but increased among men in the wait-list condition. 
3.6. Secondary Analyses. The recommended practice schedule for TM participants is twice per day, but as noted in the Method section we opted for a standard of adherence a bit more lenient than this ideal scenario. In particular, participants were considered adherent if they reported at posttest having practiced the TM technique at least once a day over the preceding week. By this standard, about two-thirds $(65 \%)$ of participants in the TM condition were adherent. A series of secondary analyses (Details of these analyses are available from the corresponding author) showed no significant differences in posttest substance use, either in rate of use or in likelihood of abstinence, for cigarettes, alcohol, or illicit drugs, between adherent and nonadherent participants in the TM condition.

\section{Discussion}

In a pre-post (three-month) randomized wait-list-controlled trial of the effects of the Transcendental Meditation (TM) program on substance use among university students, results differed by substance and by gender. There were no significant differences between TM instruction and a wait-list control condition in leading to cessation or reduction of cigarette smoking or use of illicit drugs. With respect to alcohol use, gender was a significant moderator of TM effects on abstinence as well as average intake. TM instruction did not differ from wait-list control for women, but TM instruction reduced drinking among men.

Reviews of earlier research indicating favorable effects of TM practice in lowering substance use $[4,5]$ have not reported sex differences in response to TM instruction. Similarly, a well-developed area of TM research concerns its impact in reducing blood pressure, and blood pressure reductions have been obtained in both sexes [21]. It is therefore not entirely clear why men were more responsive to TM instruction in our study with respect to reducing or eliminating alcohol consumption. As indicated in the Method section, individual TM instruction was completed by same-sex instructors, so it is possible that an instructor effect is showing up in our results as a sex difference in response to the TM program. Alternatively, male participants may simply have had more room to change their drinking habits, for they drank more at the outset (see Table 4). Given these uncertainties, we believe that future research on TM instruction and substance use should report results separately by sex in order to determine the replicability of our findings.

A further question, aside from the sex differences in intervention effects on drinking, is why the effects of TM instruction were not more favorable across the board. Earlier research [5] had led us to hypothesize that TM instruction would alter cigarette smoking, illicit drugs, and alcohol use relative to wait-list control. We believe that several explanations for the lack of more consistent, robust effects of TM instruction in this study deserve consideration.

First, the TM program may in general have the effect of reducing substance use, but this effect might be weaker in university settings. As noted in the Introduction, a majority of prior studies reporting lowered drug use after TM instruction were not conducted in college settings, were not randomized trials, or both. The influence of a peer culture conducive to substance use might offset to some extent the benefits of TM practice to the individual student's psychological well-being.

Second, TM effects on substance use may be minimized in the university context because there are other environmental mechanisms operating to reduce substance use. In other words, the university context, or at least the one studied here, might actually tend to create floor effects such that detecting any impact of TM practice is more difficult. For example, the campus on which this study was conducted is "dry," such that possession or use of alcohol on campus is a violation of university policy. Moreover, cigarette smoking is banned in most places on campus (e.g., residence halls, classroom buildings). Illicit drug use is of course illegal anywhere, but it is perhaps more likely to be detected in a setting in which one lives and works among large numbers of peers as well as authority figures such as dormitory RAs. Consistent with this explanation, cigarette smoking and illicit drug use rates were low in our sample, detracting from statistical power for showing intervention effects on these variables.

Third, our measurement methods may have been problematic, in two ways. We relied on self-report and did not include biochemical corroboration. This feature was a constant across experimental conditions, and participants were assured of the confidentiality of their responses. However, in view of the sensitive nature of some of the variables (illegal drugs and for participants under the legal drinking age alcohol use), it is possible that participants would be inclined to underreport use.

Moreover, posttest self-reports of substance use were collected with respect to the past week (cigarettes, alcohol) or past month (illicit drugs) only. We did not incorporate detailed interviews or self-monitoring methods covering the entire three-month intervention period. Self-monitoring might be obtrusive and therefore reactive in a study of an intervention such as the TM program that does not directly address substance use [22]. Future studies, however, might do well to use timeline follow-back interviews [23] at posttest to obtain a more thorough, fine-grained analysis of substance use rates and patterns of use. For example, the health implications of 7 to 9 drinks per week for a young man (our preintervention means; see Table 4) are quite different if the male student is having one drink each day than if he is having one drinking binge on the weekend.

Fourth, perhaps TM practice would show consistent effects in reducing substance use only among those who are highly motivated to seek out instruction. We did not measure participants' motivation, either in general or with specific reference to the possibility that some might have wanted to learn TM in order to reduce substance use. Participation in our project was of course voluntary, but the volunteers were solicited through conspicuous advertisements and other promotional materials. Instruction took place within walking distance of where most participants 
lived, and fees were drastically reduced-indeed, a participant who took part in both assessments received compensation equal to the cost of TM instruction for the study. Future studies could address this possibility by enrolling participants only from among those who learn about and initiate involvement in the TM program through customary referral sources and by measuring motivation directly. In the meantime, though, psychotherapy outcome data suggest that recruitment methods are unlikely to play a large role in determining results of clinical trials. Studies of "solicited volunteers" and studies of patients referred through routine clinical channels appear to obtain similar results [24].

Finally, it could be that the "dose" of TM practice in our project was insufficient to show significant reductions for both sexes in all substance use categories. One limiting factor in this respect is nonadherence. Simply being instructed in the TM program would not be expected to lower drug use if the student does not continue to practice. Only about twothirds of TM participants reported practicing at least once per day. Secondary analyses did not show a relation between adherence and substance use, but it remains possible that full adherence $(100 \%$ of those in the TM condition practicing twice per day) would have yielded stronger effects of the TM program on substance use.

Another aspect of the "dose" issue is the relatively brief (3 months) duration of our study. Both retrospective [25] and prospective [26] studies of substance use among TM practitioners have indicated that its effects may be gradual and cumulative, with cessation occurring as long as two years after initiation of TM practice. Only a longer-term randomized controlled trial of the TM program with college students could fully evaluate this possible explanation of our results.

\section{Conclusions}

In conclusion, we found no evidence of an effect of Transcendental Meditation (TM) instruction on cigarette smoking or illicit drug use among university students, but TM instruction did lower alcohol use among male participants. Given that male students are more likely than female students to have alcohol use disorders [27], the impact of TM practice on alcohol intake among men is a very encouraging result. Additional studies with larger samples of baseline substance users (particularly for cigarettes and illicit drugs), multimethod assessments of substance use, higher adherence to the recommended twice daily practice, and a longer period of TM practice would be needed before concluding definitively that the TM program does not also reduce drinking among female students or illicit drug use or cigarette smoking in college student samples of either sex.

\section{Abbreviations}

TM: $\quad$ Transcendental Meditation

ANCOVA: Analysis of covariance.

\section{Acknowledgments}

The authors thank the Abramson Family Foundation, Howard and Alice Settle, and other private donors for funding this study. They are grateful to Linda Mainquist and Mario Orsatti for coordinating and conducting the TM intervention in this study and to Kris Schumann and Sarah Weisberg for assistance with assessments.

\section{References}

[1] R. W. Hingson, T. Heeren, R. C. Zakocs, A. Kopstein, and H. Wechsler, "Magnitude of alcohol-related mortality and morbidity among U.S. College students ages 18-24," Journal of Studies on Alcohol, vol. 63, no. 2, pp. 136-144, 2002.

[2] I. Njølstad, E. Arnesen, and P. G. Lund-Larsen, "Smoking, serum lipids, blood pressure, and sex differences in myocardial infarction: a 12-year follow-up of the Finnmark study," Circulation, vol. 93, no. 3, pp. 450-456, 1996.

[3] B. D. Caudill, B. Luckey, S. B. Crosse, H. T. Blane, E. M. Ginexi, and B. Campbell, "Alcohol risk-reduction skills training in a national fraternity: a randomized intervention trial with longitudinal intent-to-treat analysis," Journal of Studies on Alcohol and Drugs, vol. 68, no. 3, pp. 399-409, 2007.

[4] C. N. Alexander, P. Robinson, and M. Rainforth, "Treating and preventing alcohol, nicotine, and drug abuse through Transcendental Meditation: a review and statistical metaanalysis," Alcoholism Treatment Quarterly, vol. 11, no. 1-2, pp. 13-87, 1994.

[5] M. A. Hawkins, "Effectiveness of the Transcendental Meditation program in criminal rehabilitation and substance abuse recovery: a review of the research," Journal of Offender Rehabilitation, vol. 36, pp. 47-65, 2003.

[6] T. I. Myers and E. J. Eisner, An Experimental Evaluation of the Effects of Karate and Meditation. Final Report for the U.S. Army Institute for the Behavioral and Social Sciences, Social Processes Technical Area, American Institutes for Research, Washington, DC, USA, 1974

[7] A. J. Ottens, "The effect of Transcendental Meditation upon modifying the cigarette smoking habit," The Journal of School Health, vol. 45, no. 10, pp. 577-583, 1975.

[8] R. Roth, Maharishi Mahesh Yogi's Transcendental Meditation: Revised \& Updated Edition, Donald I. Fine, New York, NY, USA, 1994.

[9] Maharishi, Maharishi Mahesh Yogi on the Bhagavad Gita, Penguin, New York, NY, USA, 1969.

[10] F. Travis, "Pure consciousness: distinct phenomenological and physiological correlates of 'consciousness itself,"' International Journal of Neuroscience, vol. 100, no. 1-4, pp. 77-89, 2000.

[11] F. Travis and R. K. Wallace, "Autonomic patterns during respiratory suspensions: possible markers of transcendental consciousness," Psychophysiology, vol. 34, no. 1, pp. 39-46, 1997.

[12] S. Yamamoto, Y. Kitamura, N. Yamada, Y. Nakashima, and S. Kuroda, "Medial prefrontal cortex and anterior cingulate cortex in the generation of alpha activity induced by Transcendental Meditation: a magnetoencephalographic study," Acta Medica Okayama, vol. 60, no. 1, pp. 51-58, 2006.

[13] F. Travis and R. K. Wallace, "Autonomic and eeg patterns during eyes-closed rest and Transcendental Meditation (TM) practice: the basis for a neural model of tm practice," Consciousness and Cognition, vol. 8, no. 3, pp. 302-318, 1999. 
[14] F. Travis, J. Tecce, A. Arenander, and R. K. Wallace, "Patterns of EEG coherence, power, and contingent negative variation characterize the integration of transcendental and waking states," Biological Psychology, vol. 61, no. 3, pp. 293-319, 2002.

[15] A. Newberg, F. Travis, N. Wintering, S. Nidich, A. Alavi, and R. Schneider, "Cerebral glucose metabolic changes associated with Transcendental Meditation practice," in Proceedings of the Conference on Neural Imaging, Miami, Fla, USA, August 2006.

[16] R. Jevning, R. K. Wallace, and M. Beidebach, "The physiology of meditation: a review. A wakeful hypometabolic integrated response," Neuroscience and Biobehavioral Reviews, vol. 16, no. 3, pp. 415-424, 1992.

[17] S. E. McCabe, M. Morales, J. A. Cranford, J. Delva, M. D. McPherson, and C. J. Boyd, "Race/ethnicity and gender differences in drug use and abuse among college students," Journal of Ethnicity in Substance Abuse, vol. 6, no. 2, pp. 7595, 2007.

[18] Z. A. T. Harrell and N. M. Karim, "Is gender relevant only for problem alcohol behaviors? An examination of correlates of alcohol use among college students," Addictive Behaviors, vol. 33, no. 2, pp. 359-365, 2008.

[19] S. Reinhardt, G. Bischof, J. Grothues, U. John, C. Meyer, and H. J. Rumpf, "Gender differences in the efficacy of brief interventions with a stepped care approach in general practice patients with alcohol-related disorders," Alcohol and Alcoholism, vol. 43, no. 3, pp. 334-340, 2008.

[20] P. M. O'Malley and L. D. Johnston, "Epidemiology of alcohol and other drug use among American college students," Journal of Studies on Alcohol. Supplement, supplement 14, pp. 23-39, 2002.

[21] K. G. Walton, R. H. Schneider, and S. Nidich, "Review of controlled research on the Transcendental Meditation program and cardiovascular disease: risk factors, morbidity, mortality," Cardiology in Review, vol. 12, no. 5, pp. 262-266, 2004.

[22] W. J. Korotitsch and R. O. Nelson-Gray, "An overview of self-monitoring research in assessment and treatment," Psychological Assessment, vol. 11, no. 4, pp. 415-425, 1999.

[23] L. C. Sobell and M. B. Sobell, "Timeline follow-back: a technique for assessing self-reported alcohol consumption," in Measuring Alcohol Consumption: Psychosocial and Biochemical Methods, R. Z. Litten and J. P. Allen, Eds., pp. 41-72, Humana Press, Totowa, NJ, USA, 1992.

[24] W. R. Shadish, G. E. Matt, A. M. Navarro et al., "Evidence that therapy works in clinically representative conditions," Journal of Consulting and Clinical Psychology, vol. 65, no. 3, pp. 355365, 1997.

[25] E. M. Aron and A. Aron, "The patterns of reduction of drug and alcohol use among Transcendental Meditation participants," Bulletin of the Society of Psychologists in Addictive Behaviors, vol. 2, pp. 28-33, 1983.

[26] A. Royer, "The role of the Transcendental Meditation technique in promoting smoking cessation: a longitudinal study," Alcoholism Treatment Quarterly, vol. 11, no. 1-2, pp. 221-239, 1994.

[27] W. S. Slutske, "Alcohol use disorders among US college students and their non-college-attending peers," Archives of General Psychiatry, vol. 62, no. 3, pp. 321-327, 2005. 


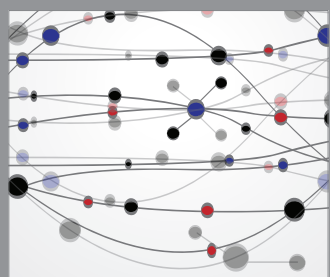

The Scientific World Journal
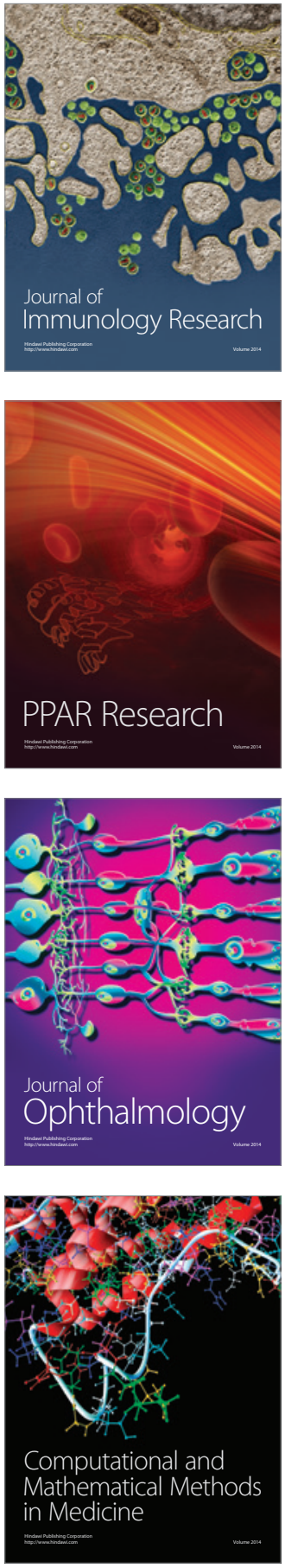

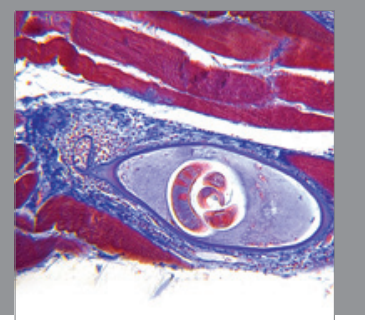

Gastroenterology

Research and Practice
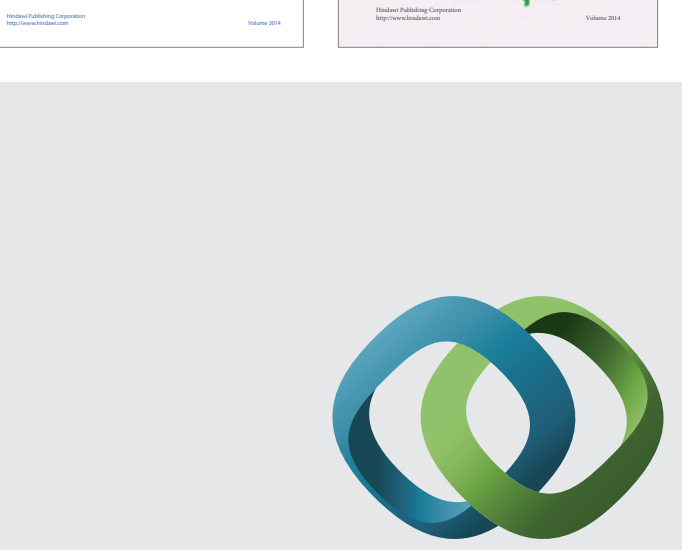

\section{Hindawi}

Submit your manuscripts at

http://www.hindawi.com
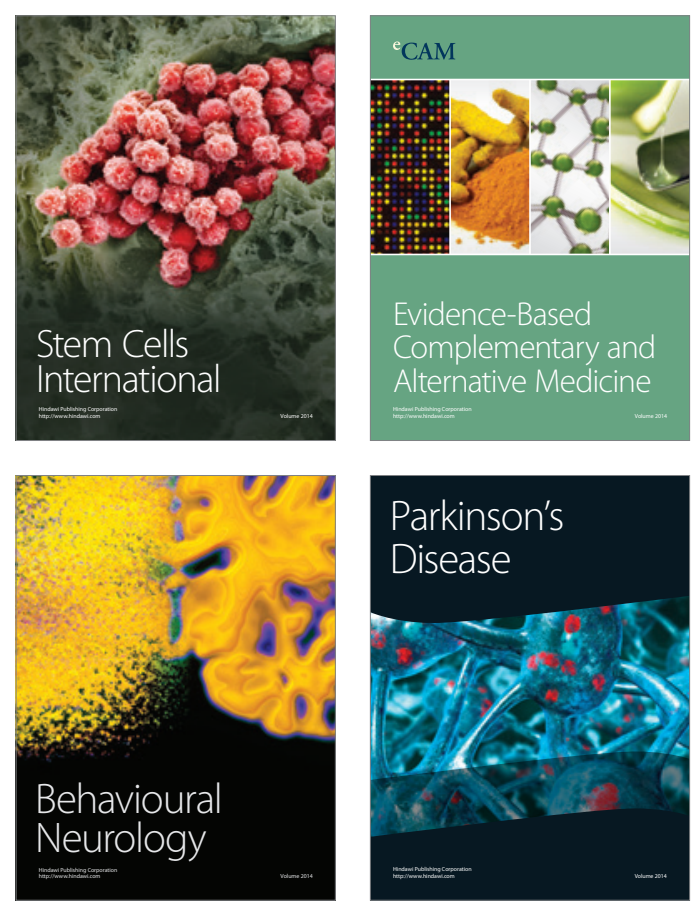

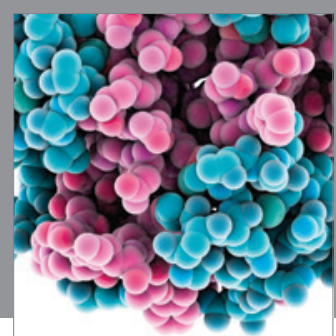

Journal of
Diabetes Research

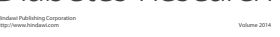

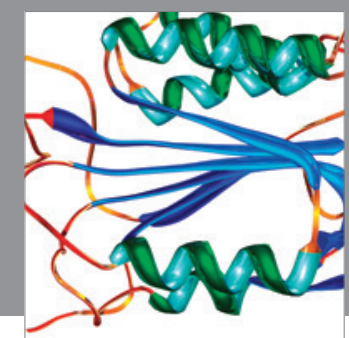

Disease Markers
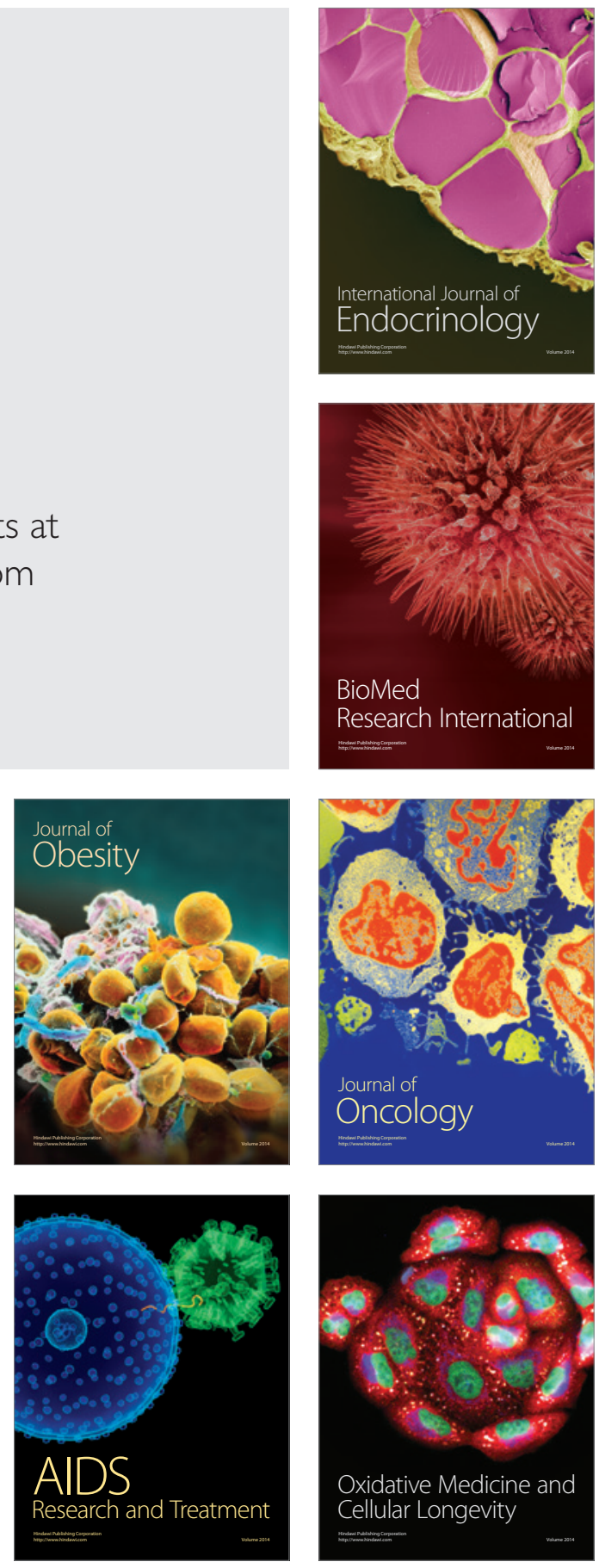